\title{
The Brand Authenticity Scale: Development and Validation
}

\author{
Van-Dat Tran \\ Banking University of HCM City, Vietnam \\ E-Mail: dattv@buh.edu.vn \\ Ching-Jui Keng, \\ National Taipei University of Technology, Taiwan \\ E-Mail: cjkeng@ntut.edu.tw
}

\begin{abstract}
The purpose of this study is to develop a brand authenticity scale by reviewing the relevant literature to identify the factors important for brand authenticity, then developing and testing the discriminant and convergent validity of measurement scales for dimensions of brand authenticity. The research method adopted includes in-depth interview and focus group interview. The procedure for scale development was: item generation, scale purification, and scale validation. This research uses qualitative and empirical methods to identify the six key dimensions of brand authenticity and develop a brand authenticity scale. As a result, a six-dimensional scale containing seventeen items was developed representing distinctive dimensions of brand authenticity: virtue, connection, realism, aesthetics, control, and originality. This research contributes to the branding literature by identifying the dimensions of brand authenticity through the development of a brand authenticity scale. Moreover, the six dimensions represent the most comprehensive understanding of brand authenticity. The brand authenticity scale can be used with confidence to examine relationships with other important constructs of interest in the future.
\end{abstract}

Keywords Authenticity, Brand authenticity, Brand authenticity scale.

\section{INTRODUCTION}

Consumers have recently started seeking out authentic brands and the brand experience. Recognizing the importance of authenticity, brand managers have responded by imbuing their brands with indications of authenticity (Beverland \& 
Luxton, 2005; Beverland et al., 2008). Authenticity research, however, has been relatively sparse. There is a need for a deeper understanding of how consumers assess authenticity to enable marketers to make key decisions that may affect the authenticity of their brand.

Many useful constructs and measurements have been developed in the branding literature, including brand personality, brand attachment and brand experience (Aaker, 1997; Thomson et al., 2009). In addition, Liao and Ma (2009) investigated the perceived characteristics of product authenticity and the idiosyncrasies and propensities of consumers who express a need for such authenticity. The construct's dimensions of authenticity in public relations and communication (Molleda, 2010) have also been defined. However, a conceptualization and scale for measuring brand authenticity have not yet been developed.

First we identify the underlying dimensions of brand authenticity, then develop a scale that can measure the strength with which a brand evokes each authenticity dimension. To identify the dimensions, we used a two-stage, multi-method approach. In Stage 1, we conducted one-on-one, in-depth interviews with 10 participants. In Stage 2, we conducted three focus group interviews with 17 participants.

Developing brand measurement is important because it brings advantages in a competitive landscape (Aaker, 1991; Adams, 1995). Building brand authenticity has been considered an important part of brand building in the marketing literature. The purpose of this dissertation is to apply the concept of brand authenticity to destination brand measurement in an integrated model. Also, the effectiveness of brand authenticity is predicted by examining consumers' behavior. This dissertation has the following objectives:

1. To define brand authenticity and explore its main dimensions.

2. To develop a comprehensive, formally validated quantitative measure of brand authenticity

3. To develop and refine the brand authenticity scale.

\section{LITERATURE REVIEW}

\section{Meaning of Authenticity}

The word "authenticity" refers to the qualities of genuineness, truth, and reality (Grayson \& Martinec, 2004). The Merriam-Webster Online Dictionary (2009) contains synonyms of authenticity such as real, actual, genuine, and bona fide. According to Boyle (2003), its synonyms include terms such as: ethical, natural, honest, simple, unspun, sustainable, beautiful, rooted, and human. In addition, Munoz et al. (2006) defined it with words such as: original, genuine, unique, traditional, and real. 
A framework of factors that contribute to authenticity has been provided by Beverland (2006), and includes: heritage and pedigree, relationship to place, method of production, commitment to quality, downplaying commercial motives and stylistic consistency. Additionally, Fine (2003) defined authenticity as: "sincere, innocent, original, genuine, and unaffected.... linked to moral authority of the creator and simultaneously to the fact that the object was made by hand, not mechanically produced". Researchers explain authenticity as original and staged (MacCannell, 1973), fabricated (Belk \& Costa, 1998), iconic, indexical, and hypothetical (Grayson \& Martinec, 2004). Bruner (1994) and numerous others (Arnould \& Price, 2000; Chronis \& Hampton, 2008; Leigh et al., 2006) have pointed out that the meaning given to authenticity is context and goal dependent.

\section{Conceptualizing of Brand Authenticity}

In the marketing literature, brands are important cultural objects (Holt, 1997, 2002) and possess significant symbolic value (Belk, 1988). Authenticity has been linked to branding (Beverland, 2005; Brown, Kozinets, \& Sherry, 2003) and consumption behavior (Holt, 1997; Belk \& Costa, 1998; Kozinets, 2001, 2002). Brands are important cultural objects (Holt, 1997, 2002) and possess significant symbolic value (Belk, 1988).

Recently, a more comprehensive conceptualization of authenticity has emerged. This conception is strongly related to self-determination theories and growth. Beverland (2005) showed that authenticity is one of the cornerstones of contemporary marketing practice, yet confusion surrounds the nature and use of authenticity in the brand arena. Holt (2002) identified how creative activities or authentic brands risked devaluing themselves by being perceived as too commercial. Brown et al. (2003) asserted that authenticity is often more contrived than real. In addition, Liao and Ma (2009) identified six characteristics of authenticity: originality, quality commitment and credibility, heritage and style persistence, scarceness, sacredness, and purity. Mason (2011) showed how the concept of authenticity has been linked to branding and consumer behavior, has been used to legitimize products and services, and adds to the market value of consumer products and cultural goods. According to McNamara (1997), consumers who seek to satisfy their need for authenticity constantly make subjective judgments of the authentic value of goods and their consumption. MacCannell (1999) argued that products and services offered for mass consumption are devoid of authenticity; therefore, authenticity can be taken as a concept contrary to most features attributed to modernity. According to Leigh et al. (2006), authenticity has been found to be associated with major corporate brands, and is central to consumer roles within almost every subculture and consumption context. Beverland et al. (2008) indicated that tradition, culture, and craft have been used to create a powerful corporate identity of 
authenticity.

Beverland (2009) contended that when consumers have different goals, they seek authenticity in different kinds of experiences. Three broad goals are identified (control, connection, and virtue) that drive the systematic selection and evaluation of different consumption experiences as being (in) authentic. Finally, authenticity is an important part of building and maintaining a successful brand because it forms a unique brand identity (Beverland, 2005) and provides a strong, favorable association (Keller, 1993).

\section{Dimensions}

To identify dimensions of brand authenticity, we next review pertinent work in the marketing literature, and on experiential marketing and management. In this literature, across a variety of disciplines, a fairly consistent set of authenticity dimensions, which are highly relevant to brands, has been proposed.

Realism: The words used to describe this characteristic in the literature are genuine, the real thing, ought to be, sincere, and true (Beverland, 2005; Grayson \& Martinec, 2004). The consumer perceives the brand not to be an imitation or a copy of another brand. The emphasis here is on the difference between the real thing and its copies or imitations.

Control: Leigh et al. (2006) showed that authenticity was related to agency and the desire of informants to achieve mastery over their environment. According to Hochschild (1983), workers in airline cabins seek control in order to reaffirm their identity as professional, skilled individuals. Fritz et al. (2017) found that authenticity has positive consequences for products' success. Napoli et al. (2016) indicated that authenticity cues of quality commitment, heritage and sincerity have differential effects on a brand's position along the authenticity continuum and, consequently, authenticity strategies.

Connection: According to Beverland (2009), connection is relating to others and their culture, time and place, and community. Arnould and Price (2000) asserted that brands and events provide the conduit for people to connect by bringing community members or loved ones together as part of an authoritative performance. Authenticity as discussed by our informants related to a feeling of being connected to important others, to culture, to time, to place, and to community. In addition, Athwal and Harris (2018) showed that authenticity is maintained by employing different strategies that emphasis various interrelated dimensions of genuineness.

Virtue: Beverland (2009) defined virtue as being true to a set of moral values. In addition, Beverland (2009) argued that authenticity captured informants who represented their authentic self by making judgments based on purity of motive. Conferring authenticity in these accounts was akin to expressing one's morals. 
Regardless of the recognized merits of brands, informants seeking virtue were intolerant of moral lapses.

\section{Generation of Scale Items}

Stage 1: One-on-one interviews: The first stage of data collection consisted of 10 oneon-one, in-depth interviews to collect information. Based on Strauss and Corbin's (1990) guidelines, we recruited 10 heterogeneous consumers from different professions for sample heterogeneity, using the snowball sampling method for the in-depth interviews. In this research we recruited participants ranging in age from 20 to 50, in order to identify the dimensions of brand authenticity, based on age. In addition, we asked participants to think of three brands (Nike, Apple, and Starbucks) and choose one that participants believed was marketed in an experiential way and describe the authenticity of experience with a brand of their choice.

The participants were strongly encouraged to think about the meaning of authenticity and their attitudes toward authenticity before starting the face-to-face indepth interview. Following the guidelines of Gubrium and Holstein (2002), we then conducted individual in-depth interviews, using qualitative methods and personal interview techniques. Each interview ranged in length from 60 to 90 minutes, and was recorded. We used a set of 15 interview questions which were developed based on a literature review and the participants' answers to an open-ended questionnaire. The interview questions pertained to their consumption experience with authentic products, motivations for consuming authentic products, extra efforts made to obtain authentic goods, benefits intended to be gained from consuming authentic goods, the individual's extent of need for authenticity, the connection between the participant and the perceived authentic goods, the importance of authentic goods to individuals and their lives, the participants' opinions, experts recommendations, and marketing communication of socalled authentic goods.

Stage 2: Focus Group Interviews: Eisenhardt (1989) has pointed out that personal interviews with four to ten participants are sufficient to generate meaningful research discovery. Additionally, Asquith (1997) suggested that a group of less than eight participants was sufficient. In this study, the six participants chosen consisted of three groups of heterogeneous consumers and used the snowball sampling method. First, we asked participants in the Stage 1 interviews to recommend suitable candidates for the focus groups. Second, we screened and selected the final participants, using their personal information, lifestyle, and consumption attitudes (Leigh et al., 2006). Finally, we moderated three sessions of focus group interviews using the same questions we used in Stage 1. Each focus group interview was recorded and ranged in length from 60 
to 90 minutes. Based on the focus groups and the existing literature (Churchill, 1979), an initial pool of 41 items was then created.

The objective of this section was to generate specific items for the proposed dimensions of brand authenticity and to select the items that have face validity in terms of describing relevant brand authenticity through two stages of interviews. To generate the initial items, we conducted an extensive literature search and review focused on concepts related to the four dimensions of authenticity, including: reality, control, connection, and virtue.

\section{Pretest}

To generate a potential list of scale items, 10 qualitative interviews were conducted with undergraduate students at National Taipei University of Technology. Participants were asked to think of a brand that they felt was authentic. A wide range of brands were mentioned, from technology companies (Apple) to clothing companies (Nike) to food markets and cafes (Starbucks). To avoid any bias resulting from the researcher's understanding of brand authenticity, no initial definition of brand authenticity was presented to the participants. After participants identified a brand that they felt was authentic, participants explained their reasoning and why they felt this brand was authentic. By keeping the description open-ended, we left the participants free to choose or focus on any concept or dimension of brand authenticity they felt was relevant. Reasons for why the participants thought a brand was authentic were recorded and analyzed later.

\section{Reliability Analysis and Exploratory Factor Analysis}

In this study, we asked a sample of students $(\mathrm{N}=250)$ to indicate the extent to which the 41 items described their authenticity with each of three brands listed $(1=$ "strong disagree", and 7 = "strong agree"). In addition, we prepared three versions of the questionnaire; each version included one brand (e.g. Nike, Apple, and Starbucks). A total of 250 questionnaires were distributed to consumers in each region comprising 129 males and 121 females aged 14-50 years old, and we successfully got 241 participants, resulting in a 96.4 percent response rate-sufficient for a survey of this type. 
Table 1. Exploratory factor analysis

\begin{tabular}{|c|c|c|c|c|c|c|}
\hline Items & Virtue & Connection & Realism & Aesthetic & Control & Originality \\
\hline $\begin{array}{l}\text { This brand is inauthentic } \\
\text { because of low labor cost for } \\
\text { long working. }\end{array}$ & 0.859 & & & & & \\
\hline $\begin{array}{l}\text { This brand explains the morality } \\
\text { and honesty of the particular } \\
\text { company. }\end{array}$ & 0.850 & & & & & \\
\hline $\begin{array}{l}\text { This brand needs to note friendly } \\
\text { environment. }\end{array}$ & 0.822 & & & & & \\
\hline $\begin{array}{l}\text { This brand claims that they use } \\
\text { recycle materials. }\end{array}$ & 0.814 & & & & & \\
\hline
\end{tabular}

This brand includes most functions that are practical in daily usage and authentic value.

Advertising of this brand sometimes is too exaggerated so that you feel unreal.

Culture, time, place, and community also make authenticity.

Authenticity of this brand means reliable.

This brand prefers to be true to them.

Products of this brand are made genuine and honesty

\begin{tabular}{l} 
Authenticity of this brand means \\
aesthetic. \\
The authenticity is considered as \\
prestige of this brand. \\
This brand is distinctive image, \\
good word-of-mouth and good \\
quality. \\
$\begin{array}{l}\text { This brand is authentic because } \\
\text { people should have good faith } \\
\text { and confidence in their products. }\end{array}$ \\
$\begin{array}{l}\text { Authenticity of this brand is very } \\
\text { important to consumers. }\end{array}$ \\
$\begin{array}{l}\text { Authenticity of this brand fulfills } \\
\text { on every possible level. }\end{array}$ \\
$\begin{array}{l}\text { I hope everything is original } \\
\text { enough. }\end{array}$ \\
$\begin{array}{l}\text { I like to consume authentic } \\
\text { products. }\end{array}$ \\
\hline
\end{tabular}


Following Churchill's (1979) model, the first step in purifying the measurement instrument was to calculate item-total correlations and alpha coefficients to eliminate garbage items. By grouping 41 items according to the four conceptual dimensions from which these items were derived. In addition, the corrected item-to-total correlations were plotted in descending order, and items with item-to-total correlations below 0.5 were deleted. Because each item's corrected item-to-total correlation was above $0.5,23$ items were deleted at this stage. All of these items were found to be clearly related to their constructs. Reliability was evaluated by assessing the internal consistency of the items representing each factor using Cronbach's alpha. The reliability of each factor was as follows: reality $=0.83$; control $=0.78$; connection $=0.82$ and virtue $=0.82$. In addition, each of these 18 items had a corrected item-to-total correlation of above 0.50 .

An exploratory factor analysis revealed six factors with eigenvalues greater than 1. The six factors explained $71 \%$ of the variance. After varimax rotation, a clean factor structure emerged. The three reality items loaded on the first factor, the three aesthetic items loaded on the second factor, the three control items loaded on the third factor, the two originality items loaded on all five factors and the four virtue items loaded on all six factors.

\section{Confirmatory Factor Analyses (CFA)}

The goodness-of-fit for each model was assessed by examining the chi-square statistic, the comparative fit index (CFI), and the root-mean-square error of approximation (RMSEA), NFI, IFI, and CFI, the latter of which needed to be greater than 0.90 (Hair et al., 1998). GFI and AGFI index exceeds 0.8. Chi-square/df is smaller than 5 and RMSEA is less than 0.08 (Hair et al., 1998). Additionally, the local fit of the model was assessed by following local fit criteria: indicator reliability greater than 0.30 ; standardized factor loading greater than 0.60 and significant t-value; an average variance explained (AVE) greater than 0.50; and a composite reliability greater than 0.60 (Bagozzi \& Yi, 1988).

We formulated an SEM using AMOS 17.0 to analyze our model. The confirmatory factor analyses revealed that the best model was the six-factor model with correlated factors (for details, see Table 2). The fit measures for that model suggested a reasonable fit: The goodness-of-fit index $(\mathrm{GFI})=.90$, the comparative fit index $(\mathrm{CFI})=.93$, and the root mean square error of approximation $($ RMSEA) $=.072$, and chi-square/df 2.09, $p<.001$, all indicating acceptable fit. One item of virtue dimension was removed because of loading $<0.5$. 
Table 2. Confirmatory factor analysis (CFA) fitting Indices

\begin{tabular}{|c|c|c|c|}
\hline Factor & $\begin{array}{l}\text { Factor } \\
\text { loading }\end{array}$ & $\mathrm{CR}$ & AVE \\
\hline Virtue & & 0.845 & 0.65 \\
\hline $\begin{array}{l}\text { This brand is inauthentic because of low labor cost for long } \\
\text { working. }\end{array}$ & 0.785 & & \\
\hline $\begin{array}{l}\text { This brand explains the morality and honesty of the } \\
\text { particular company. }\end{array}$ & 0.838 & & \\
\hline This brand needs to note friendly environment. & 0.782 & & \\
\hline Connection & & 0.75 & 0.515 \\
\hline $\begin{array}{l}\text { This brand includes most functions that are practical in daily } \\
\text { usage and authentic value. }\end{array}$ & 0.780 & & \\
\hline $\begin{array}{l}\text { Advertising of this brand sometimes is too exaggerated so } \\
\text { that you feel unreal. }\end{array}$ & 0.734 & & \\
\hline Culture, time, place, and community also make authenticity. & 0.655 & & \\
\hline Realism & & 0.814 & 0.6 \\
\hline Authenticity of this brand means reliable. & 0.759 & & \\
\hline This brand prefers to be true to them. & 0.750 & & \\
\hline Products of this brand are made genuine and honesty. & 0.810 & & \\
\hline Aesthetics & & 0.802 & 0.56 \\
\hline Authenticity of this brand means aesthetic. & 0.673 & & \\
\hline The authenticity is considered as prestige of this brand. & 0.795 & & \\
\hline $\begin{array}{l}\text { This brand is distinctive image, good word-of-mouth and } \\
\text { good quality. }\end{array}$ & 0.792 & & \\
\hline Control & & 0.791 & 0.559 \\
\hline $\begin{array}{l}\text { This brand is authentic because people should have good } \\
\text { faith and confidence in their products. }\end{array}$ & 0.681 & & \\
\hline Authenticity of this brand is very important to consumers. & 0.772 & & \\
\hline Authenticity of this brand fulfills on every possible level. & 0.789 & & \\
\hline Originality & & 0.68 & 0.624 \\
\hline I hope everything is original enough. & 0.812 & & \\
\hline I like to consume authentic products. & 0.771 & & \\
\hline
\end{tabular}

\section{Reliability and Validity}

Reliability was evaluated by assessing the internal consistency of the items representing each factor using Cronbach's alpha. The reliability of each factor was as follows: virtue $=0.81$, connection $=0.75$, reality $=0.82$, aesthetics $=0.8$, control $=0.81$ and originality $=0.77$. These values are acceptable and demonstrate that the instrument is reliable. Further evidence of the reliability of the scale is provided in Table 2, which shows the composite reliability and average variance extracted scores of the different factors obtained (Fornell \& Larcker, 1981; Hair et al., 2006). Composite reliability (CR) 
of all the latent variables is greater than the acceptable limit of 0.70 (Carmines \& Zeller, 1988). The average variance extracted for all the factors is greater than or equal to 0.5 , which is acceptable (Fornell \& Larcker, 1981).

Convergent validity was assessed by examining the factor loadings and average variance extracted of the constructs, as suggested by Fornell and Larcker (1981). All the indicators had significant loadings on the respective latent constructs $(p<0.001)$ with values varying between 0.6 and 0.84 (Table 2). In addition, the average variance extracted (AVE) for each construct is greater than or equal to 0.50 , which further supports the convergent validity of the constructs.

Discriminant validity was tested by comparing the average variance extracted (AVE) with the corresponding inter-construct squared correlation estimates (Fornell \& Larcker, 1981). From Table 3 it can be inferred that the square root of the AVE values of all the real factors-honesty, control, connection, genuineness and virtue are greater than the inter-construct correlations, which supports the discriminant validity of the constructs. Thus, the measurement model demonstrated discriminate validity.

Table 3. Discriminant validity and correlations among the constructs

\begin{tabular}{llccccc}
\hline & Virtue & Connection & Realism & Aesthetic & Control & Originality \\
\hline Virtue & $0.806^{* *}$ & & & & & \\
Connection & $0.713^{* *}$ & $0.717^{* *}$ & & & & \\
Realism & $0.668^{* *}$ & $0.688^{* *}$ & $0.774^{* *}$ & & & \\
Aesthetics & $0.718^{* *}$ & $0.689^{* *}$ & $0.703^{* *}$ & $0.748^{* *}$ & & \\
Control & $0.693^{* *}$ & $0.670^{* *}$ & $0.680^{* *}$ & $0.660^{* *}$ & $0.747^{* *}$ & \\
Originality & $0.707^{* *}$ & $0.658^{* *}$ & $0.668^{* *}$ & $0.718^{* *}$ & $0.656^{* *}$ & $0.789^{* *}$ \\
\hline
\end{tabular}

Notes: ${ }^{*} \mathrm{p}<0.05,{ }^{*} * \mathrm{p}<0.01 ; \mathrm{n}=241$

\section{DISCUSSION}

The branding literature offers no prior research that develops and tests a scale or examines the issues and factors that are important for developing brand authenticity. Previous qualitative research on brand authenticity has not identified key dimensions using a quantitative methodology. Beverland (2006) had a discussion about wines topic. His research identifies six attributes of authenticity: heritage and pedigree, stylistic consistency, quality commitments, relationship to place, method of production and downplaying commercial interests. Though previous qualitative research studies have suggested various indicators for authenticity, it is crucial to identify through empirical analysis the key indicators of authenticity. This study develops the scale measurements through a comprehensive literature review, and tests the validity of the scale. In this research, the 17-item brand authenticity scale captures in a reliable and stable way six 
dimensions of brand authenticity: virtue, connection, reality, aesthetics, control and originality. The scale is easy to administer, and it is internally consistent and reliable. Importantly, the brand authenticity scale is related to, but distinct from, other brand scales. There are six factors that emerge with significant factor loadings. We identified the six key significant dimensions of brand authenticity and started to measure brand authenticity for various brands and companies. However, before these dimensions of brand authenticity are used in experimental research, the dimensions and brand authenticity scale should be tested for generalizability. From both of these studies, virtue, connection, realism, aesthetics, control and originality are the six key dimensions and opportunities for a brand to be authentic. If a brand is able to capitalize on one or more of these dimensions, the brand may be viewed as authentic and receive additional benefits from this perception.

Moreover, the six dimensions represent the most comprehensive understanding of brand authenticity. The brand authenticity scale can be used with confidence to examine relationships with other important constructs of interest in the future. Importantly, brand experience has a behavioral impact-it positively affects satisfaction through brand equity.

The scale will be useful not only in academic research but also in marketing practice. As marketers engage in projects to understand and improve the authenticity their brands provide for their customers, they can use the scale for assessment, planning, and tracking purposes. In addition to its managerial usefulness, the brand authenticity scale enables researchers to advance marketing theory in the area of marketing and branding. For instance, through using the brand authenticity scale, researchers can evaluate how different marketing strategies affect the value of brands.

The authors suggest replicating this research using different services and different analytical techniques such as structural equation modeling and confirmatory factor analysis. The relative importance of different components of brand authenticity can also be ascertained. Research is also recommended to find out the effects of different marketing strategies on brand authenticity.

Finally, the proposed brand authenticity measure is entirely consumer-based and does not incorporate the views of other stakeholders such as the firm, employees, or channel members. Future research can draw on this study to develop a total authenticity measure that integrates the authenticity created for different stakeholders of the brand.

\section{FURTHER RESEARCH}

Further research should focus on brand authenticity leading to brand trust for both functional products and experiential products. As authenticity is a way to build brand trust, companies have an incentive to actively highlight their authenticity or take actions 
to strengthen it. Though building authenticity is not an easy task and it is difficult to be authentic, brands can benefit from the effects of brand authenticity and gain a critical competitive advantage over their competitors.

Finally, further research should focus on the antecedents and long-term consequences of brand authenticity. In addition, although we have shown the relations of brand authenticity, both directly and indirectly, with short-term consequences, such as satisfaction, the question arises as to whether brand authenticity affects customers' lifetime values (Rust, Zeithaml, \& Lemon, 2000; Vogel, Evanschitzky, \& Ramaseshan, 2008). That is, 1) Can brand authenticity build customer loyalty? and 2) How should marketers manage brands to create authenticity that builds such loyalty?

\section{REFERENCE}

Aaker, D. (1991). Managing brand equity. Ontario: The Free Press.

Aaker, J. L. (1997). Dimension of brand personality. Journal of Marketing Research, 34(3), 347-356. https://doi.org/10.2307/3151897

Adams, J. (1995). Brands at the crossroads. American Advertising, 11(3), 18-20.

Arnould, E. J., \& Price, L. L. (2000). Authenticating acts and authoritative berformances: Questing for self and community. In S. Ratneshwar, D. G. Mick, and C. Huffman (Eds.), The why of consumption: Contemporary perspectives on consumer motives, goals, and desires. London: Routledge.

Asquith, J. (1997). The effects of group size on the outcome of focus group sessions. Management Research News, 20(12), 1-15. https://doi.org/10.1108/eb028582

Athwal, N., \& Harris, L.C. (2018). Examining how brand authenticity is established and maintained: The case of the Reverso. Journal of Marketing Management, 34(3-4), 347-369. https://doi.org/10.1080/0267257x.2018.1447008

Bagozzi, R. P., \&Yi, Y. (1988). On the evaluation of structural equation models. Journal of the Academy of Marketing Science, 16, 74-94.

https://doi.org/10.1177/009207038801600107

Belk, R. W., \& Costa, J. A. (1998). The mountain man myth: A contemporary consuming fantasy. Journal of Consumer Research, 25(3), 218-240.

https://doi.org/10.1086/209536

Beverland, M. B. (2005). Crafting brand authenticity: The case of luxury wines. Journal of Management Studies, 42(5), 1003-1029. https://doi.org/10.1111/j.14676486.2005.00530.x

Beverland, M. B. (2006). The real thing: Branding authenticity in the luxury wine trade. Journal of Business Research, 59(2), 251-258.

https://doi.org/10.1016/j.jbusres.2005.04.007

Beverland, M. B. (2009). Building brand authenticity: 7 habits of iconic brands. London, 
UK: Palgrave Macmillan. https://doi.org/10.1057/9780230250802

Beverland, M. B., \& Luxton, S. (2005). Managing integrated marketing communication (IMC) through strategic decoupling: How luxury wine firms retain brand leadership while appearing to be wedded to the past. Journal of Advertising, 34(4), 103-116. https://doi.org/10.1080/00913367.2005.10639207

Beverland, M. B., Lindgreen, A., \& Vink, M. W. (2008). Projecting authenticity through advertising: Consumer judgments of advertisers' claims. Journal of Advertising, 37(1), 5-15. https://doi.org/10.2753/joa0091-3367370101

Boyle, D. (2003). Authenticity: Brands, fakes, spin and the lust for real life, London, UK: Harper Perennial.

Brakus, J.J., Schmitt, B. H., \& Zarantonello, L. (2009). Brand experience: What is it? How is it measured? Does it affect loyalty? Journal of Marketing, 73(3), 52-68. https://doi.org/10.1509/jmkg.73.3.52

Brown, S., Kozinets, R.V., \& Sherry Jr. J. (2003). Teaching old brands new tricks: Retro branding and the revival of brand meaning. Journal of Marketing, 67(3) 19-33. https://doi.org/10.1509/jmkg.67.3.19.18657

Bruner, E. M. (1994). Abraham Lincoln as authentic reproduction: A critique of postmodernism. American Anthropologist, 96(2), 397-415.

https://doi.org/10.1525/aa.1994.96.2.02a00070

Carmines, E.G., \& Zeller, R.A. (1988). Reliability and validity assessment. Beverly Hills, CA: Sage. https://doi.org/10.4135/9781483340333.n350

Chronis, A., \& Hampton, R.D. (2008). Consuming the authentic Gettysburg: How a tourist landscape becomes an authentic experience. Journal of Consumer Behaviour, 7(2), 111-126. https://doi.org/10.1002/cb.241

Churchill, G. A. (1979). A paradigm for developing better measures of marketing constructs. Journal of Marketing Research, 16(1), 64-73.

https://doi.org/10.2307/3150876

Eisenhardt, K. M. 1989. Building theories from case study research. Academy of Management Review, 14(4), 532-550. https://doi.org/10.4135/9781473915480.n52

Fine, G. A. (2003). Crafting authenticity: The validation of identity in self-taught art. Theory and Society, 32(2), 153-180.

Fornell, C., Larcker, D.G. (1981). Evaluating structural equation models with unobservable variables and measurement error. Journal of Marketing Research 18(1), 39-50. https://doi.org/10.2307/3151335

Fritz, K., Schoenmueller, V \& Bruhn, M. (2017). Authenticity in branding - Exploring antecedents and consequences of brand authenticity. European Journal of Marketing, 51(2), 324-348. https://doi.org/10.1108/ejm-10-2014-0633

Grayson, K., \& Martinec, R. (2004). Consumer perceptions of iconicity and indexicality 
and their influence on assessments of authentic market offerings, Journal of Consumer Research, 31(2), 296-312. https://doi.org/10.1086/422109

Gubrium, J. F., \& Holstein, J. A. (2001). Handbook of Interview Research: Context \& Method. London, UK: Sage. http://dx.doi.org/10.4135/9781412973588

Hair Jr., J. F., Anderson, R. E., Tatham, R. L., \& Black, W. C. (1998). Multivariate data analysis ( $5^{\text {th }}$ Edition), NJ: Prentice Hall.

Hair Jr., J. F., Black, W. C., Babin, B. J., Anderson, R. E., \& Tatham, R. L. (2006). Multivariate data analysis (6th Edition). NJ: Pearson.

Hochschild, A. R. (1983). The managed heart: Commercialization of human feeling. Berkeley, CA: University of California Press. https://doi.org/10.5465/amr.1985.4278667

Holt, D. B. (1997). Poststructuralist lifestyle analysis: Conceptualizing the social patterning of consumption in postmodernity? Journal of Consumer Research, 23(4), 326-350. https://doi.org/10.1086/209487

Holt, D. B. (2002). Why do brands cause trouble? A dialectical theory of consumer culture and branding. Journal of Consumer Research 29(1), 70-90. https://doi.org/10.1086/339922

Keller, K. L. (1993). Conceptualizing, measuring and managing customer-based brand equity. Journal of Marketing, 57(1), 1-22. https://doi.org/10.2307/1252054

Kozinets, R. V. (2001). Utopian enterprise: Articulating the meanings of star Trek's culture of consumption. Journal of Consumer Research, 28(1), 67-89. https://www.jstor.org/stable/10.1086/321948

Leigh, T. W., Cara, P., \& Shelton, J. (2006). The consumer quest for authenticity: The multiplicity of meanings within the MG subculture of consumption. Journal of the Academy of Marketing Science, 34(4), 481-493.

https://doi.org/10.1177/0092070306288403

Liao, S., \& Ma, Y. Y. (2009). Conceptualizing consumer need for authenticity. International Journal of Business and Information, 4(1), 89-114.

MacCannell, D. (1973). Staged authenticity: Arrangements of social space in tourist settings. American Journal of Sociology, 79(3), 589-603.

https://doi.org/10.1086/225585

MacCannell, D. (1999). The tourist: A new theory of the leisure class. Berkeley, CA: University of California Press.

Mason, J. (2011). Aesthetic authenticity: Consummatory experience in the marketplace. (Doctoral dissertation). Retrieved from Oklahoma State University, Pub No: 3474685.

McNamara, C. (1997). Authenticity. How to remain authentic with yourself and others. Retrieved April 17, 2006, from 
http://www.managementhelp.org/prsn_wll/authentc.htm

Molleda, J. C. (2010). Authenticity and the construct's dimensions in public relations and communication research. Journal of Communication Management, 14(3), 223236. https://doi.org/10.1108/13632541011064508

Munoz, C. L., Wood, N. T., \& Solomon, M. R. (2006). Real or blarney? A cross-cultural investigation of the perceived authenticity of Irish pubs. Journal of Consumer Behaviour, 5(3), 222-234. https://doi.org/10.1002/cb.174

Napoli, J, Dickinson-Delaporte, S., \& Beverland, M (2016). The brand authenticity continuum: Strategic approaches for building value. Journal of Marketing Management, 32(13-14), 1201-1229.

https://doi.org/10.1080/0267257x.2016.1145722

Rust, R. T., Zeithaml, V. A., \& Lemon, K. N. (2000). Driving customer equity: How customer lifetime value is reshaping corporate strategy. New York: The Free Press. https://doi.org/10.1108/ijsim.2002.13.1.107.1

Thomson, M., MacInnis, D. J., \& Park, C. W. (2005). The ties that bind: Measuring the strength of consumers' emotional attachments to brands. Journal of Consumer Psychology, 15(1), 77-91. https://doi.org/10.1207/s15327663jcp1501_10

Vogel, V., Evanschitzky, H., \& Ramaseshan, B. (2008). Customer equity drivers and future sales, Journal of Marketing, 72(11), 98-108.

https://doi.org/10.1509/jmkg.72.6.98

Dr. Van- Dat Tran (Corresponding author) is currently an assistant professor of Department of Marketing, Banking University of HCM city. His research focuses on Brand Management, E-Commerce and Interactive marketing.

Dr. Ching-Jui Keng is currently a professor of Department of Business Management, National Taipei University of Technology. His current research focuses on E-Commerce, Interactive Marketing and Information Technology Management. 